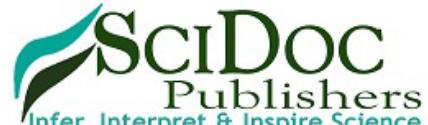

\author{
International Journal of Dentistry and Oral Science (IJDOS) \\ ISSN: $2377-8075$
}

\title{
Super-Oxidized Water against Conventional Irrigants in Smear Layer Removal using Endovac Irrigating System: A Scanning Electron Microscopic Study
}

Research Article

Gowrish S*, Urvashi Sodvadiya, Vandana Sadananda

Department of Conservative Dentistry and Endodontics, A. B. Shetty Memorial Institute of Dental Sciences, Nitte (Deemed to be University), Deralakatte, Mangaluru - 575018, Karnataka, India.

\section{Abstract}

Background: The success of endodontic therapy is governed by qualitative instrumentation and meticulous cleaning of the root canal system with irrigants. An irrigant is indeed required to reach the optimum ideal requirements without any side effects. The present study was designed to evaluate and compare the efficacy of a commercially available super-oxidized water (OXUM) in the removal of the smear layer with the gold standard (5\% Sodium Hypochlorite and 17\% Ethylenediaminetetraacetic acid)using the EndoVac irrigating system.

Materials and Methods: 30 human extracted straight mandibular premolar teeth were randomly divided into three groups $(n=10)$ based on the type of irrigant to be employed in the course of the root canal preparation. Group A: $5 \% \mathrm{NaOCl}+17 \%$ EDTA, Group B: Super-oxidized Water, and Group C: Saline (Control). The teeth were split longitudinally and investigated using Field- Emission Scanning Electron Microscope (Zeiss LEO 1530, Oberkochen, Germany) to analyze the amount of smear layer present. Torabinejad et al.'s criteria were used to score the images. Friedman test and Mann Whitney test were applied to identify if there is any significant difference among the values $(\mathrm{P}=<0.05)$.

Results: The control group showed the highest smear layer scores. However, the difference between group A and group B was not statistically significant. Additionally, the smear layer was removed significantly even from the apical third of the root canal.

Conclusion: Super-oxidized water (OXUM) proved to be an alternative to the conventional irrigants in the smear layer removal. EndoVac Irrigating System demonstrated enhanced smear layer removal in the apical third.

Keywords: Ethylenediaminetetraacetic Acid (EDTA); EndoVac Irrigating System; Smear Layer; Super-Oxidized Water OXUM; Sodium Hypochlorite.

\section{Introduction}

Meticulous debridement and thorough disinfection of the root canal space is crucial for successful endodontic treatment. This can be achieved by qualitative mechanical instrumentation (using hand and rotary system) and effective irrigation. [1] Several microCT studies (Peters et al., 2001; Jeon et al., 2003) concluded that even with careful instrumentation, inaccessible areas in the root canal system (i.e., isthmus and fins) remained untouched. $[2,3]$ This emphasizes the use of novel irrigants and irrigating systems during the routine endodontic treatment.

Biomechanical preparation using hand or rotary instruments pro- duces considerable quantities of debris which is called the smear layer. According to McComb and Smith, the smear layer contains inorganic components like dentinal chips and odontoblastic process residues, along with organic components like necrotic pulp tissue and bacteria. [4] Though the presence of the smear layer is controversial, it must be removed from the infected root canals to reduce the chances of reinfection. The most commonly used combination, 5.25\% Sodium Hypochlorite $(\mathrm{NaOCl})$ with $17 \%$ Ethylenediaminetetraacetic acid (EDTA), is effective in removing the smear layer and flushing out the debris. [5, 6] Super-oxidized water (OXUM, Alkem Labs, Mumbai, India), a novel endodontic irrigantis an electrochemically processed aqueous solution. Since it isrich in reactive oxygen species, it is a potent antimicrobial solution that is available for use in medicine as well as in the dental

*Corresponding Author:

Dr. Gowrish S,

Department of Conservative Dentistry and Endodontics, A. B. Shetty Memorial Institute of Dental Sciences, Nitte (Deemed to be University), Deralakatte, Mangaluru - 575018, Karnataka, India.

E-mail: drgowrishs@nitte.edu.in

Received: August 08, 2021

Accepted: August 30, 2021

Published: September 04, 2021

Citation: Gowrish S, Urvashi Sodvadiva, Vandana Sadananda. Super-Oxidized Water against Conventional Irrigants in Smear Layer Removal using Endovac Irrigating System: A Scanning Electron Microscopic Study. Int J Dentistry Oral Sci. 2021;8(9):4275-4279. doi: http://dx.doi.org/10.19070/2377-8075-21000870

Copyright: Dr. Gowrish S ${ }^{\odot} 2021$. This is an open-access article distributed under the terms of the Creative Commons Attribution License, which permits unrestricted use, distribution and reproduction in any medium, provided the original author and source are credited. 
field. $[7,8]$

Despite the plethora of technological advancements seen over the last several decades, very few systems can deliver the irrigant in the most apical area of a root canal.[9] Moreover, to increase the accessibility to the apical area, the needle must be placed till the working length which further increases the chances of forcing the solution into periradicular tissue.[10] However, the apicalnegative pressure irrigating system (EndoVac, Kerr Dental, USA) claims to deliver solutions safely and effectively up to the estimatedworking length and reduces the risk of irrigants being extruded into the periradicular region. [11]

Hencethe present study was aimed to evaluate and compare the efficacy of a commercially available super-oxidized water in smear layer removal with the gold standard using the EndoVac irrigating system.

\section{Materials And Methods}

\section{Sample selection}

Ethical approval was granted from the NITTE (Deemed to be University), Mangalore, India (Cert. No: ABSM/EC/82/2018) to collect 30 extracted sound human mandibular single-rooted premolar teeth within one month of extraction. The teeth were disinfected in 5\% chloramine $-\mathrm{T}$ solution for 48 hours and were preserved in distilled water until use. Based on the macroscopic and radiographic evaluation, the teeth with caries, restoration, visible crack, abnormal morphology, and multiple root canal were excluded and a total of 30 teeth were selected.

\section{Root canal instrumentation}

Based on the irrigation solution to be used in the procedure all the specimens were randomly divided into three study groups with 10 teeth each (Figure 1). Group A: 5\% NaOCl + 17\% EDTA, Group B: Super-oxidized Water Group C: Saline (Control group). Access opening was performed using high-speed diamond bur with copious water spray. Pulp extirpation was done using barbed broaches (Dentsply Maillefer, Ballaigues, Switzerland). Patency was assured by inserting the number 10 hand stainless steel K-file (Dentsply Maillefer, Ballaigues, Switzerland) in the root canal until the tip of the file was visible at the apical foramen. The working length was determined by deductingone $\mathrm{mm}$ from the length measured, which was further verified radiographically.

The coronal one third was flared with sizes 2-3 Gates-Glidden drills (Dentsply Maillefer, Ballaigues, Switzerland). All the root canals were instrumented using the number 20 hand stainless steel K-file (Dentsply Maillefer, Ballaigues, Switzerland) followed by ProTaper Gold rotary files (ProTaper Gold Rotary Files, Dentsply Maillefer, Ballaigues, Switzerland) up to F2 as per the manufacturer's instructions in a crown down manner.[12] In between, recapitulation was done with the number 10 stainless steel $\mathrm{K}$-file to ensure the patency of the canal. With the change of each instrument, the canals were irrigated according to the groups usingnegative pressureirrigating systemas per the manufacturer's instructions (Figure 2). After completion of root canal preparation, final rinsing of canals was done using $3 \mathrm{ml}$ of distilled water to flush out the debris. The paper points (Dentsply Maillefer, Ballaigues, Switzerland) were used to dry the canals.

\section{Sample preparation for SEM}

Longitudinal grooves weremade on the buccal and lingual surfaces of the roots without perforating the canal using a diamond disk at a slow speed. Each specimen was split into two halves with a chisel and were stored in distilled water until SEM analysis. The superior aspect of each section was coded.The coded halves were dehydrated in ethanol followed by desiccation for 24 hours. Sputter coating was done of each specimen with gold and then the coronal third (10-14mm from the apex), middle third (6-7mm from the apex), and apical third (1-3 $\mathrm{mm}$ of the apex) of each specimen from each group.[13] The prepared specimens were evaluated under Field- Emission Scanning Electron Microscope (Zeiss LEO 1530, Oberkochen, Germany). Photographs of the surface were taken at $4000 \mathrm{X}$ magnification (Figure3-5). The images were scored based on Torabinejad et al.'s criteria:[14]

Score 1 - No smear layer. No smear layer on the surface of the root canal; all tubules are clean and open.

Score 2 - Moderate smear layer. No smear layer on the surface of the root canal, but tubules contain debris.

Score 3 - Heavy smear layer. The smear layer covers root canal surfaces and tubules.

Collected data based on SEM images of each study group were analyzed statistically by using Friedman testand Mann Whitney U test.

\section{Results And Discussion}

The SEM images of all the study groups are shown in Figure 3-5. Friedman's test showed that there is no significant difference in the removal of the smear layer from each third of the canal in

Figure 1. Division of samples based on irrigants used during root canal preparation.

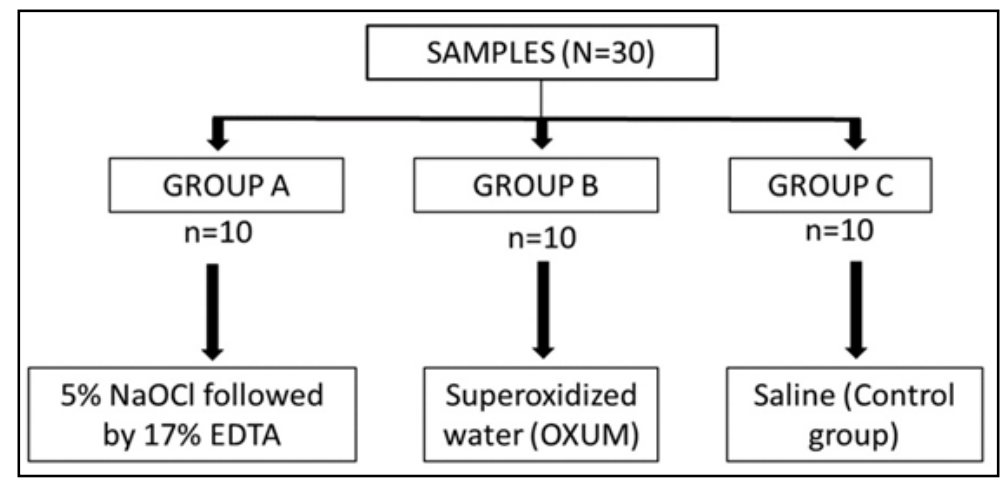


Figure 2. (a) Clinical set up of the EndoVac Irrigating system. (b) Photographic presentation of Microcannula which is used to remove gross debris from the root canal system.

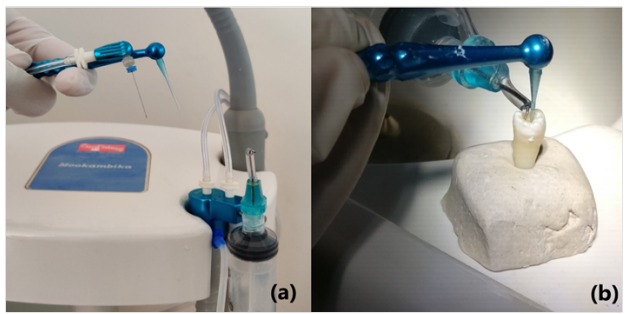

Figure 3. SEM images (group A). The coronal, middle, and apical third of the root canal irrigated with $5.25 \% \mathrm{NaOCl}$ followed by $17 \%$ EDTA. Clean root canal surface can be seen in the coronal and middle third of the canal while the presence of debris on the canal wall can be seen in some area of the apical third. The opening of the dentinal tubules can be well appreciated in the coronal, middle, and apical third of the canal.

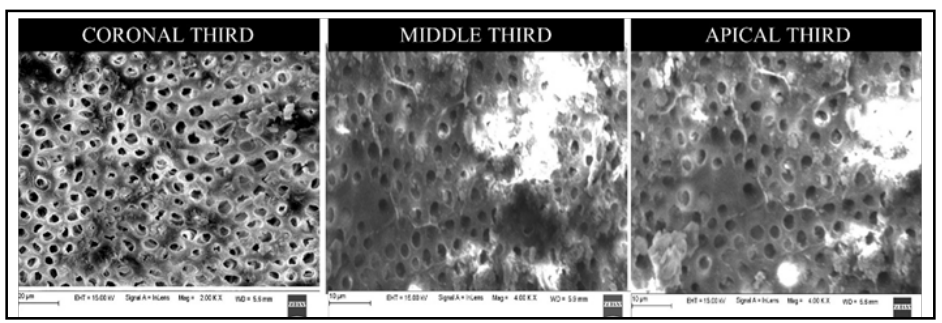

Figure 4. SEM images (group B). The coronal, middle, and apical third of the root canal irrigated with superoxidized water. A clean root canal surface can be seen in the coronal third of the canal while the presence of debris on the canal wall can be seen in some area of the middle and apical third. The opening of the dentinal tubules can be well appreciated in the coronal, middle, and apical third of the canal.

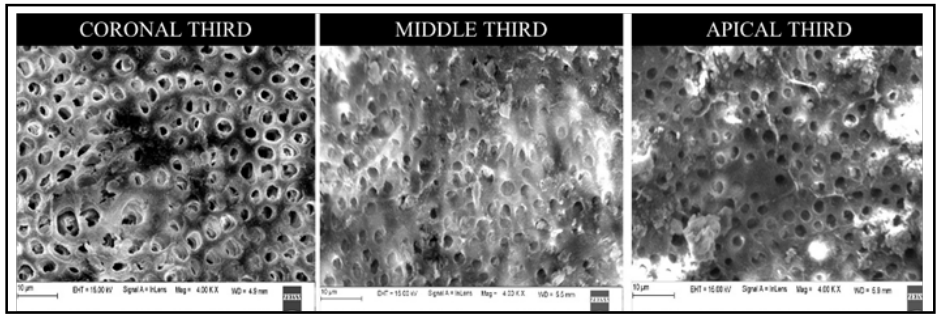

Figure 5. SEM images (group C: Control group). The coronal, middle, and apical third of the root canal irrigated with saline. The root canal surface can be seen fully covered with debris in the coronal, middle, and apical third of the canal while the opening of very few dentinal tubules can be seen only in the coronal third of the canal.

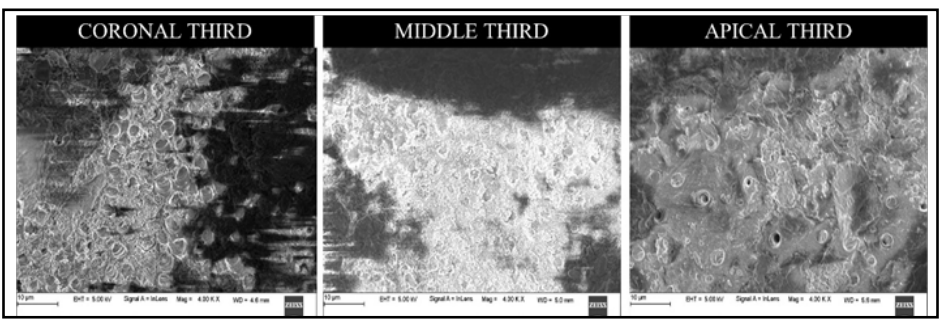

all the study groups (Table 1). Hence, Mann Whitney was performed, and it showed no significant difference in the removal of the smear layer when group A and group B were compared (P-value: >0.05) (Table 2).

The highest mean score was reported in the control group (Table 1). Hence, the heavy smear layer covering the root canal surface and tubules was found in each third of the root canal in all the specimens of group C (Figure 5).

The biological and clinical rationale of endodontic treatment is to completely clean and shape the canals to receive an optimal fluidtight seal of radicular space. Smear layer formation during root canal preparation prevents penetration of irrigantsinto the dentinal tubules. Inadequate cleaning of the canal results in delayed healing and subsequent secondary infection. In the present study, both combinations of $5.25 \% \mathrm{NaOCl}$ and EDTA and super-oxidized waterremoved the smear layer efficiently from the entire length of the canals. A study conducted by M. Rathakrishnan et al showed no significant difference between super-oxidized water and EDTA for removal of smear layer. In their study, super-oxidized water was evaluated as a final rinse. Additionally, it was less erosive to the dentinal structure than EDTA.[8]

As suggested by Wu et al (2001), single-rooted mandibular premolars with straight single canal were selected as study specimensto maintain standardization by avoiding anatomic complexity and variations. Furthermore, this was confirmed by taking radiographs of each sample.[15] 
Table 1: Comparative evaluation (Intergroup) of coronal, middle and apical third of each group for removal of smear layer.

\begin{tabular}{|c|c|c|c|c|c|c|}
\hline & Group & $\mathbf{N}$ & Mean (SD) & \multicolumn{3}{|c|}{ Mann Whitney U test (p-value) } \\
\hline & & & & A vs B & A vs $C$ & B vs $C$ \\
\hline \multirow{3}{*}{ Coronal } & Group A & 10 & $1(0)$ & \multirow{3}{*}{$0.32(\mathrm{NS})$} & \multirow{3}{*}{$<0.001 *$} & \multirow{3}{*}{$<0.001^{*}$} \\
\hline & Group B & 10 & $1.1(0.32)$ & & & \\
\hline & Group C & 10 & $2.8(0.42)$ & & & \\
\hline \multirow{3}{*}{ Middle } & Group A & 10 & $1(0)$ & \multirow{3}{*}{0.15 (NS) } & \multirow{3}{*}{$<0.001 *$} & \multirow{3}{*}{$<0.001 *$} \\
\hline & Group B & 10 & $1.2(0.42)$ & & & \\
\hline & Group C & 10 & $3(0)$ & & & \\
\hline \multirow{3}{*}{ Apical } & Group A & 10 & $1.2(0.42)$ & \multirow{3}{*}{$0.62(\mathrm{NS})$} & \multirow{3}{*}{$<0.001 *$} & \multirow{3}{*}{$<0.001 *$} \\
\hline & Group B & 10 & $1.3(0.48)$ & & & \\
\hline & Group C & 10 & $3(0)$ & & & \\
\hline
\end{tabular}

$*_{\mathrm{p}}<0.05$ Statistically significant

$\mathrm{p}>0.05$ Non-Significant, NS

Table 2. Comparative evaluation (Intragroup) of each group in coronal, middle and apical third to check efficacy of EndoVac Irrigating system.

\begin{tabular}{|l|c|c|c|c|c|}
\hline \multirow{2}{*}{ Groups } & & \multirow{2}{*}{ N } & \multirow{2}{*}{ Mean (SD) } & \multicolumn{2}{|c|}{ Friedman test } \\
\cline { 1 - 1 } & & & & Chi Square Value & P value \\
\hline & Coronal & 10 & $1(0)$ & \multirow{2}{*}{} & \multirow{2}{*}{$0.14(\mathrm{NS})$} \\
\hline Group A & Middle & 10 & $1(0)$ & & \multirow{2}{*}{$0.22(\mathrm{NS})$} \\
\hline & Apical & 10 & $1.2(0.42)$ & & \multirow{2}{*}{3} \\
\cline { 1 - 4 } Group B & Coronal & 10 & $1.1(0.32)$ & & \multirow{2}{*}{$0.14(\mathrm{NS})$} \\
\hline & Middle & 10 & $1.2(0.42)$ & & \\
\hline & Apical & 10 & $1.3(0.48)$ & & \\
\hline
\end{tabular}

The most commonly used irrigant is a combination of $5.25 \%$ $\mathrm{NaOCl}$ with $17 \%$ EDTA. $5.25 \% \mathrm{NaOCl}$ dissolves the necrotic tissue and presents antimicrobial activity (organic content of the smear layer) whereas inorganic content could be decalcified by $17 \%$ EDTA.[14, 16, 17] Super-oxidized water is a powerful antibacterial agent and rich in reactive oxygen species. It contains oxidized solution ( $\mathrm{H} 2 \mathrm{O})$, sodium hypochlorite, hypochlorous acid ( $\mathrm{HOCl})$, hydrogen peroxide $\left(\mathrm{H}_{2} \mathrm{O}_{2}\right)$, ozone $\left(\mathrm{O}_{3}\right)$, Chlorine dioxide $\left(\mathrm{Cl}_{2} \mathrm{O}\right)$, sodium hydroxide $(\mathrm{NaOH})$, sodium carbonate $\left(\mathrm{Na}_{2} \mathrm{CO}_{3}\right)$, and sodium chloride $(\mathrm{NaCl})$. [7] The bacterial cell wall is denatured due to the osmolarity differences between the intracellular and extracellular environment, and the generation of free radicals from the solution. [18, 19] Solovyea et al.; 2000, combined hypochloric acid, hydrogen peroxide, and chlorine dioxide to compare the efficacy with $3 \% \mathrm{NaOCl}$ alone, and a combination showed a higher amount of smear layer removal.[20] According to Cobankara et al; 2010, $13.8 \%$ Chlorine dioxide and $5.25 \% \mathrm{NaOCl}$ are equally efficient in removing the organic content of the smear layer. [21] Hydroxyl ions (OH-) released from sodium hydroxide increases $\mathrm{pH}$ and stability of the solution. Besides, it flushes out the debris and cleanses the root canals due to its detergent action which is supported by Dube et al; 2018.[22] According to Hata et al; 2001, chloride ions (Cl-) released from oxidative potential water removed the inorganic content of smear layer. Hence it could be proposed that $\mathrm{Cl}$ - ions released from super-oxidized water remove the inorganic content of the smear layer. [23]

Apart from necrotic pulp and microorganisms, $\mathrm{NaOCl}$ rapidly damages the collagen of superficial dentin which might further affect the bonding of resin-based sealer to root dentin. [24] Though $\mathrm{NaOCl}$ solution is not expensive and has a long shelf life, precautions must be taken when it is being used as an irrigant during the root canal treatment. Because of its cytotoxic effects, inadvertent injections of irrigant instead of anesthesia, extrusion of irrigant beyond the apical foramen, and in the oral cavity lead to hypochlorite accidents.[25] According to Gwawehr et al, a combination of $\mathrm{NaOCl}$ and EDTA allows maintaining the calcium-binding capacity of EDTA but at the same time, it drastically decreases tissue degrading capacity of NAOCl by reducing the amount of released chlorine.[26] While super-oxidized water is rich in reactive oxygen at neutral $\mathrm{pH}$. It is stable, easy to use, and has a long shelf life. Moreover, it removes the organic and inorganic components of the smear layer and exposes the intact collagen fibers in root dentin. [8] Hence bonding of resin-based sealer to root dentin might not be affected by super-oxidized water.

Negative pressure irrigating system (EndoVac, Kerr Dental, USA) claims to deliver the irrigant till the working length without being 
extruded inthe periapical area.[27] In the present study, negative pressure irrigating system was used andit was effective in smear layer removal even at the apical area of the root canal. This result is an agreement with the previous studies conducted by Howard R K;2011 and Jiang L M; 2012. [28, 29]

Aseptic environment and meticulous debridement of the complex root canal is the main aim of endodontic treatment. As per the current study, super-oxidized water is statistically equivalent to a combination of 5\% sodium hypochlorite and 17\% EDTA in smear layer removal. Furthermore, super-oxidized water has limited adverse effects than sodium hypochlorite. Hence, it can be used as an alternative irrigant in the cases where the smear layer removal is highly recommended.

\section{Conclusion}

The novel irrigant, super-oxidized water alone facilitated the complete smear layer removal. Moreover, EndoVac enhanced the removal of the smear layer in the apical third area. However, various factors like saliva, blood, pulp, and crevicular fluid as well as the complexity of the root canal system could affect the treatment outcome in clinical conditions. Hence more in vivo studies need to be conducted to establish 'super-oxidized water' as a routine endodontic irrigant.

\section{References}

[1]. Abd Al Gawad RY, Hanafy RMH ( 2020) Success rate of three capping materials used in pulpotomy of primary molars: A randomized clinical trial. Saudi Dent J:1-8.

[2]. Gisoure EF (2011) Comparison of three pulpotomy agents in primary molars: A randomised clinical trial. Iran Endod J 6:11-14.

[3]. Mohammad SG, Baroudi K (2015) Assessment of the potential of Allium sativum oil as a new medicament for non- vital pulpotomy of primary teeth. J Int Soc Prevent Communit Dent 5:314-320.

[4]. Chakraborty R, Sen S (2017) Aloe vera-the atavistic herb used in dentistry. World J Pharm Res 6:356-365.

[5]. Gonna S, Ghoname N, Kabbash A, Yagi A (2019) Efficacy of Aloe Vera as A Pulpotomy Agent in Children Primary Teeth : Clinical and Radiographic Studies. J Gastroenterol Hepatol Res 8:2946-2951.

[6]. Maqbool H, Ali MA, Haq UU, Shah SA (2020) Comparing the efficacy of Aloe vera gel versus ferric sulphate as a pulp medicament in vital pulpotomy of deciduous. Khyber Med Univ J 12:10-14.

[7]. Mettlach SE, Zealand CM, Botero TM, Boynton JR, Majewski RF, et al. (2013) Comparison of mineral trioxide aggregate and diluted formocresol in pulpotomized human primary molars: 42 -month follow-up and survival analysis. Pediatr Dent 35:1-20.

[8]. Ahmed SS, Gadalla LM, Elmeadawy SH, Badria F (2018) The Efficacy of Aloe vera Gel in Treatment of Oral Lichen Planus. Int Dent Med J Adv Res 2015:1-6.

[9]. Gupta N, Bhat M, Prabha Devi, Girish (2010) Aloe-Vera : A Nature's Gift to Children. Int J Clin Pediatr Dent 3:87-92.

[10]. Bossù M, Iaculli F, Giorgio G Di, Salucci A, Polimeni A, et al. (2020) Dif- ferent Pulp Dressing Materials for the Pulpotomy of Primary Teeth : A Systematic Review of the Literature. J Clin Med 9:1-23.

[11]. Yousry YM, Abd Al Latif AE, Abd Al Gawad RY (2020) Clinical and Radiographic Evaluation of Vital Pulpotomy in Primary Molar Using Antioxidant Mix as A Novel Pulotomy Medication Versus Formcresol: Adv Dent J 3:12-23.

[12]. Samarh SN, Khalaf NA, Hajhamad MM (2017) Evidence based medical use of aloe vera extracts, short review of literature. Int J Res Med Sci 5:41984202.

[13]. Ahlawat S, Gulia N, Khatkar B (2013) Effect of plant maturity on leaf growth, yield and physicochemical properties of aloe vera gel. AgroFOOD Ind hi-tech 24:22-24.

[14]. Nazemi N, Khalighi-Sigaroodi F, Monfared A (2017) Processing and stabilization of Aloe Vera leaf gel by adding chemical and natural preservatives. RJP 4:24

[15]. Rahman S, Carter P, Bhattarai N (2017) Aloe Vera for Tissue Engineering Applications. J Funct Biomater 8:1-17.

[16]. Dhar V, Marghalani AA, Crystal Y, Kumar A, Ritwik P, et al. (2017) Use of Vital Pulp Therapies in Primary Teeth with Deep Caries Lesions.Pediatr Dent 39:E146-E159.

[17]. Kent DG, Knapp DJ, Kannan N (2020) Survey Says: "COVID-19 Lockdown Hits Young Faculty and Clinical Trials." Stem Cell Reports 15:1-5.

[18]. Durmus B, Tanboga I (2014) In Vivo evaluation of the treatment outcome of pulpotomy in primary molars using diode laser, formocresol, and ferric sulphate. Photomed Laser Surg 32:289-295.

[19]. Atasever G, İleri Keçeli T, Uysal S, Güngör HC, Ölmez S (2019) Primary molar pulpotomies with different hemorrhage control agents and base materials: A randomized clinical trial. Niger J Clin Pract 22:305-312.

[20]. aman E, Görken F, Erdem AP, Sepet E, Aytepe Z (2012) Effects of folk medicinal plant extract ankaferd blood stopper ${ }^{\circ}$ in vital primary molar pulpotomy. Eur Arch Paediatr Dent 13:197-202.

[21]. Pratima B, Chandan GD, Nidhi T, Nitish I, Sankriti M, et al. (2018) Postoperative assessment of diode laser zinc oxide eugenol and mineral trioxide aggregate pulpotomy procedures in children : A comparative clinical study. J Indian Soc Pedod Prev Dent 36:308-314.

[22]. Chakraborty A, Dey B, Jana S (2018) A Nonconventional Approach to Formocresol Pulpotomy. Int J Clin Pediatr Dent 11:490-495.

[23]. Subramanyam D, Somasundaram S (2020) Clinical and Radiographic Evaluation of Aloe vera vs Formocresol as a Pulpotomy Medicament in Primary Molars : A Double Blinded Randomized Controlled Trial. Int J Clin Pediatr Dent 13:139-143.

[24]. Al-Dahan ZA, Zwain AM, Al-Assadi AH (2013) Clinical and Radiographical Evaluation of Pulpotomy in Primary Molars Treated with Pulpotec (PD), Formocresol and Mineral Trioxide Aggregate (MTA). J Baghdad Coll Dent 25:164-170.

[25]. Silva LL, Silva L, Sakai VT, Lopes CS, Silveira AP, et al. (2019) Comparison between calcium hydroxide mixtures and mineral trioxide aggregate in primary teeth pulpotomy: A randomized controlled trial. J Appl Oral Sci $27: 1-8$.

[26]. AAPD (2014) Guideline on Pulp Therapy for Primary and Immature Permanent Teeth. AAPD Ref Man 36:242-250.

[27]. Sajadi F (2014) Clinical and Radiographic Findings after Using Formocresol and Elaeagnus angustifolia Fruit Powder for Pulpotomy of Primary Molar Teeth. Wulfenia J21:262-278.

[28]. Kalra M, Garg N, Rallan M, Pathivada L, Yeluri R(2017) Comparative evaluation of fresh Aloe barbadensis plant extract and mineral trioxide aggregate as pulpotomy agents in primary molars: A 12-month follow-up study. Contemp Clin Dent.Jan 8(1):106-111.

[29]. Havale R, Anegundi RT, Indushekar KR, Sudha P(2013) Clinical and Radiographic Evaluation of Pulpotomies In Primary Molars With Formocresol, Glutaraldehyde and Ferric Sulphate. OHDM12(June):24-31. 